Observatório de

Inovação do Turismo

BRASIL

Revista Acadêmica

ISSN 1980-6965

www.ebape.fgv.br/revistaoit

Sensacional!

\title{
Os conhecimentos dos organizadores de eventos em primeiros socorros
}

Knowledge of organizers of events in first aid

Bruna Dorabiallo de Oliveira

Luciane Patrícia Oliari

\section{Resumo}

No artigo aqui apresentado, busca-se discutir o conhecimento em primeiros socorros dos organizadores de eventos, entendendo que tal conhecimento é decisivo para a tomada de decisão em acontecimentos inesperados. Objetiva-se com o estudo verificar essas noções dos organizadores de eventos e, para tanto, a princípio, realizaram-se pesquisas bibliográficas e documentais para investigar os conceitos sobre eventos, primeiros socorros e legislação vigente. Depois, descreveram-se as principais situações de urgência e emergência em eventos, elencadas em forma de perguntas no questionário, e, por fim, por meio da aplicação do instrumento de pesquisa, verificou-se qual devia ser o comportamento do organizador de eventos em situações de urgência e emergência. Como resultado da pesquisa, concluiu-se que há conhecimentos prévios sobre primeiros socorros, porém não suficientes para atender de maneira adequada a situações de urgência e emergência nos eventos. Ao finalizar o estudo, sugeriu-se a criação de um material de consulta permanente

Artigo recebido em 05 de Setembro de 2013 e aceito em 06 de Janeiro de 2014. 
sobre primeiros socorros para organizadores de eventos e a composição de uma ação de capacitação específica para esse público.

Palavras-chave: eventos, organizador de eventos, primeiros socorros, legislação

\section{Abstract:}

The presented article is intended to discuss the importance of knowledge of first aid for the event organizers, understanding that this knowledge is crucial for unexpected events. The main objective of this study was to investigate the knowledge of the organizers of events in first aid and to achieve therefore first took place literature searches and document verifying the concepts of events, first aid and law. In a second step, are described major emergencies and emergency events and listed as a question in the questionnaire, finally, through the application of the survey instrument was shown that the behavior of the event planner in urgent and emergency. As a result of the research it was found that no previous knowledge about first aid, but it is not sufficient to meet adequately the situations and emergency events. Concluding the study, suggested the creation of a permanent reference material on first aid for event organizers and specific training for this audience.

Key words: events, event planner, first aid, legislation

\section{Introdução}

Organizar eventos é uma tarefa complexa que envolve grandes responsabilidades. Com base no conceito descrito por Meirelles (1999, p. 23),

[...] eventos são ações planejadas, que podem ser mercadológicas ou institucionais, são desenvolvidas com o objetivo de atingir resultados qualificados e quantificados junto a seu público-alvo de 
forma a criar conceito e estabelecer imagem, através da aproximação entre os participantes.

O organizador de eventos é responsável por administrar as ideias contidas na concepção do evento e torná-las realidade, gerenciando desde a idealização até a realização do evento. Exige-se desse profissional a capacidade de gerir diversos fornecedores ao mesmo tempo e atuar de maneira proativa em situações inesperadas, entre elas as de urgência e de emergência médica que podem ser o limite entre a vida e a morte.

De acordo com o CFM - Conselho Federal de Medicina - (1995, p.1), por meio da Resolução n. ${ }^{0} 1.451 / 95$, urgência e emergência definem-se como "ocorrência imprevista de agravo à saúde com ou sem risco potencial de vida, cujo portador necessita de assistência médica imediata" (urgência); e "constatação médica de condições de agravo à saúde que impliquem risco iminente de vida ou sofrimento intenso, exigindo, portanto, tratamento médico imediato" (emergência).

Nas situações de urgência e emergência, é preciso atendimento imediato no início dos sinais e sintomas, que podem ser de origem clínica (doença) ou traumática (ferimento). A esse atendimento imediato dá-se o nome de primeiros socorros, que são os procedimentos adotados antes da chegada de um profissional qualificado da área de saúde ou da ambulância quando uma pessoa é vítima de qualquer acidente ou mal súbito. Além dos danos físico, emocional e material, intercorrências de saúde podem gerar divulgações negativas sobre o evento, seu organizador, patrocinador e demais envolvidos.

Conforme Quilici e Timerman (2011), no Brasil, o atendimento de primeiros socorros é pouco difundido, fazendo-se necessário que a população saiba quais procedimentos se devem realizar e como fazê-los para que se minimizem as complicações das vítimas.

Diante do exposto, no presente estudo, verificaram-se os conhecimentos dos organizadores de eventos em primeiros socorros. Para 
atingir tais objetivos, consultou-se a legislação vigente referente ao atendimento de urgência e emergência em eventos; descreveram-se as principais situações de urgência e emergência em eventos; e, por meio da aplicação de questionários aos organizadores de eventos, indicaram-se seus comportamentos em situações de urgência e emergência nos eventos com base nos resultados da pesquisa.

\section{Fundamentação Teórica}

\subsection{Eventos}

Os eventos são parte significativa no fluxo programado de pessoas para determinada localidade, por motivações diversas. Esse fluxo pode ser visto como fonte de consumo, movimentação de novos visitantes na localidade, ou fenômeno multiplicador de negócios. Assim define Andrade (2007, p. 99-100) evento:

[...] é todo fenômeno capaz de alterar determinada dinâmica da economia. Não se pode fugir da alternativa de que existem grande complexidade e heterogeneidade no campo dos eventos e sua influência sobre viagem e turismo.

Há diversas definições para eventos, tanto do ponto de vista turístico, como mercadológico e de comunicação. Porém Britto e Fontes (2002, p. 21) apresentam um significado para o termo que congrega as diversas definições apresentadas na literatura da área.

Muito mais que acontecimento de sucesso, festa, linguagem de comunicação, atividade de relações públicas ou mesmo estratégia de marketing, o evento é a soma de esforços e ações planejadas com o objetivo de alcançar resultados definidos junto a seu público-alvo. 
Como o evento é a ação planejada, a forma de divulgação de uma empresa, marca ou ocasião social e a imagem negativa que pode ser gerada na ocasião de intercorrências mal resolvidas também devem ser consideradas. Citam-se, como exemplos, as notícias divulgadas conforme os excertos expostos abaixo:

- Reportagem exibida no Jornal Nacional, na edição de 20 de novembro de 2012

Uma noite que deveria ser de festa para um casal de noivos terminou em tragédia. $O$ noivo morreu ao cair sobre um copo de vidro, que estava no bolso de sua calça. Os cacos de vidro cortaram a veia femoral dele, por onde passa todo o sangue que sai da perna em direção ao coração. Ele perdeu muito sangue e chegou morto ao hospital

- Notícia de Fabrício Calado Moreira, veiculada no Diário de São Paulo, em 5 de março de 2007.

Uma armação metálica desabou durante um baile de formatura no salão do Clube Espéria, em Santana, na zona norte, ferindo 11 pessoas, segundo a Secretaria de Segurança Pública. Segundo testemunhas, a queda aconteceu logo após a Orquestra Saigon terminar seu show para formandos do Colégio Serrano Guardia, de Guarulhos. Quando um DJ subiu ao palco para tocar música eletrônica, um funcionário pôs-se a desmontar a armação que segurou a iluminação de palco para a banda. Cerca de duas mil pessoas estavam no salão, segundo a assessoria do clube.

A imagem divulgada por meio de notícias pode alterar a imagem do responsável ${ }^{1}$ pela organização e causar repercussões negativas na mídia para pessoas, marcas e empresas.

${ }^{1} \mathrm{O}$ organizador de eventos é considerado um prestador de serviços turísticos, de acordo com a Lei n. ${ }^{\circ}$ 11.771 de 2008. Conforme o art. 34, inciso IV, é dever do organizador de eventos "manter, no exercício de suas atividades, estrita obediência aos direitos do consumidor". Dessa forma, o prestador de serviços deve atuar com o respaldo no Código de Defesa do Consumidor. 
O evento pode ser classificado de diversas maneiras, uma vez que diferentes classificações podem estar associadas a ele, considerando-se objetivo, dimensões, público e local de realização. É possível descrever evento em relação ao público quando se qualifica uma ocasião como evento aberto ou fechado, por exemplo. Pode-se também segmentar os eventos, de acordo com a frequência em que eles ocorrem, como anuais, semestrais, mensais etc. Há inúmeras formas de efetuar essa classificação, porém nesse estudo é necessário levar em consideração os termos utilizados nas normativas que apresentam as regras de pronto atendimento em eventos. Em leis, normas e procedimentos consultados para essa pesquisa, comumente se encontram termos técnicos referentes a eventos classificados conforme objetivos e dimensões.

A classificação dos eventos por dimensão ocorre de maneira mais simplista do que a por objetivo ou interesse. Na primeira, o critério é o número de participantes ou convidados, o que traz como consequência a necessária estrutura de atendimento, pois os eventos são elencados em pequenos, médios e grandes. Há algumas discordâncias na literatura acerca desse assunto, porém se consideram eventos pequenos aqueles que envolvem um público de até duzentas pessoas. Já como mensuração de evento de porte médio estima-se a participação de um público entre duzentos e quinhentos participantes. Por fim, julgam-se eventos de grande porte aqueles que mobilizam pelo menos quinhentos participantes (BRITTO; FONTES, 2002, p. 135). A atenção em relação ao número de participantes em um evento é de grande importância, uma vez que parte da legislação existente que regulamenta os eventos aborda tal tema de acordo com a classificação por dimensão.

Para ingressar na área de eventos e desenvolver-se como bom profissional, é preciso estar atento a algumas características e habilidades pessoais, como curiosidade e sede por conhecimento; organização; conhecimento técnico; criatividade; iniciativa e comprometimento; bom relacionamento; conhecimento de mercado, bom senso e autoconfiança; 
capacidade de liderança e facilidade de trabalhar em equipe e atitude empreendedora (MATIAS, 2004). O organizador de eventos é responsável por administrar as ideias contidas na concepção do evento e torná-las realidade, gerenciando todas as etapas, desde a idealização até a realização do evento.

\subsection{Primeiros Socorros}

Primeiros socorros são procedimentos de emergência para atender, ainda no local do acidente, as vítimas de trauma, urgências ou emergências clínicas, garantindo a segurança local, avaliando o estado da vítima, estabilizando os sinais vitais, imobilizando e transportando os pacientes para a unidade hospitalar e/ou até que o socorro especializado chegue (MORAES, 2010; QUILICI; TIMERMAN, 2011). Esse atendimento, iniciado ainda no local do acidente, contribui significativamente para a manutenção da integridade física e/ou psíquica do indivíduo em uma situação de risco.

Conforme o Código Penal brasileiro, art. 135 da Lei n.o 2.848 de 7 de dezembro de 1940, é "crime de omissão de socorro":

Deixar de prestar assistência, quando possível de fazê-lo sem risco pessoal, à criança abandonada ou extraviada, à pessoa inválida ou ferida, ao desamparado ou em grave e iminente perigo; ou não pedir nesses casos, o socorro da autoridade pública. PENA: detenção de um ano e seis meses, ou multa, podendo a pena ser aumentada de metade, se da omissão de socorro resultar lesão corporal de natureza grave, e triplicada se resultar em morte.

Os princípios básicos de primeiros socorros são: conhecer os sinais vitais, reconhecer situações que coloquem a vida em risco (tanto da vítima, quanto de socorrista e curiosos), segurança (para vítima, socorrista e curiosos), sinalização do local do acidente, aplicar respiração e circulação artificiais (quando necessário), controlar sangramentos (quando necessário), minimizar o risco de outras lesões e complicações (manipulação incorreta de vítima/lesões), 
confortar e tranquilizar a vítima, utilizando tom de voz moderado e inspirandoIhe confiança, e providenciar assistência médica e transporte quando necessários (QUILICI; TIMERMAN, 2011; SANTORO, 2011).

Os conhecimentos sobre primeiros socorros devem ser uma competência básica para qualquer cidadão, entretanto exige o domínio de habilidades que podem ser adquiridas com treinamentos específicos. Características de primeiros socorros: saber o que não deve ser feito, para onde ligar e sinalizar o local do acidente. Tais procedimentos farão toda a diferença no processo de recuperação da vítima (FLEGEL, 2002 apud DONADEL, 2001).

Conforme Oliveira, Parolin e Teixeira Jr. (2004 apud ROSSA; FERREIRA, 2005), um estudo realizado pelo médico norte americano D. Trunkey, M. D., em 1982, mostra que há uma redução de $20 \%$ a $50 \%$ no número de óbitos, quando se realiza um atendimento pré-hospitalar (primeiros socorros) adequado a vítimas.

Para melhor entendimento das situações de urgência e emergência em eventos, conceituam-se abaixo as situações mais comuns encontradas nessas ocasiões, citadas por profissionais atuantes na área, assim como os materiais indispensáveis que o organizador deve manter em seu kit de primeiros socorros: lanterna pequena; gazes estéreis; ataduras; compressas; curativos adesivos; soro fisiológico 0,9\%; esparadrapo/micropore; tesoura; luvas; máscaras de RCP descartáveis; termômetro clínico; talas flexíveis; álcool gel; sal/açúcar.

É importante avaliar os sinais vitais, pois evidenciam o funcionamento e as alterações da função corporal. Entre os inúmeros sinais que são utilizados na prática diária para o auxílio do exame clínico, destacam-se: pressão arterial, pulso, temperatura corpórea e respiração. Por estarem os mesmos relacionados com a própria existência da vida, recebem o nome de sinais vitais (HORTA,1979).

Outra observação importante é a da parada respiratória. Sabe-se que ocorre quando há interrupção ou diminuição significativa dos batimentos do coração, o que provoca a redução da quantidade satisfatória de sangue 
circulante. Costuma suceder simultaneamente à parada respiratória, a parada cardiorrespiratória. A realização imediata de reanimação cardiopulmonar (RCP), até mesmo por leigos, contribui significativamente para o aumento das taxas de sobrevida das vítimas de parada cardíaca. Conforme estudo desenvolvido por programas internacionais, as taxas de sobrevivência estão na ordem de 49 a 74\% (QUILICI; TIMERMAN, 2011).

Não é possível esquecer-se das obstruções das vias aéreas por corpo estranho (OVACE) - , isto é, toda situação que impeça, total ou parcialmente, o trânsito de ar até os alvéolos pulmonares. A OVACE pode ser classificada em leve (parcial) e grave (total). Na obstrução leve, é possível a vítima manter "boa" troca gasosa, podendo tossir fortemente para expulsar o que causou o engasgo. $\mathrm{Na}$ obstrução grave, ocorre dificuldade respiratória com trocas gasosas insuficientes, tosse silenciosa, cianose e incapacidade de falar. A vítima pode segurar o pescoço com as mãos, e esse é o sinal universal de asfixia (QUILICl; TIMERMAN, 2011).

Há, ainda, a síncope que se caracteriza pela perda de consciência de curta duração que não necessita de manobras de reanimação. A causa fundamental da síncope (desmaio) é a diminuição da atividade cerebral em decorrência do fluxo sanguíneo cerebral. Então, para manter a oxigenação cerebral, o corpo desliga, mantendo mínima atividade com mínimo gasto de energia. Alguns sintomas que antecedem a síncope, chamados de vertigem, são eles: palidez (pele descorada), sudorese (suor), pulso rápido e fraco e perda dos sentidos, tontura, visão embaraçada e súbita perda da consciência (MORAES, 2010).

Há os traumas (fratura, entorse, luxação) que são lesões do sistema musculoesquelético que, na maioria, não causam risco de vida imediato. Essas lesões podem atribuir-se a fatores intrínsecos (internos), como anormalidade do alinhamento ósseo, fraqueza muscular, frouxidão ligamentar, e a fatores extrínsecos (externos), como calçados, superfícies, condições ambientais 
adversas etc. São lesões musculoesqueléticas mais comuns: fraturas, luxações e entorses (MORAES, 2011; SANTORO, 2011). Ressalte-se que a fratura é o rompimento ou quebra de um segmento ósseo e pode ser simples, quando não oferece risco imediato à vida da vítima, como a fratura de ossos curtos (rádio, ulna, ossos da mão etc.), ou grave, quando a lesão oferece risco à vida da vítima pela instabilidade hemodinâmica provocada (perda de sangue), como a fratura de fêmur e pelve que pode ter perda sanguínea de até dois mil mililitros, mesmo quando é uma fratura fechada (MORAES, 2011). Já a entorse ocorre quando uma articulação entre dois ossos é forçada além de seus limites fisiológicos, o que leva à lesão do tendão, músculo ou ligamento próximo a uma articulação (estruturas que sustentam as articulações) (MORAES, 2011). Quanto à luxação, é uma lesão em que as extremidades ósseas que formam uma articulação ficam deslocadas, permanecendo desalinhadas e sem contato entre si (MORAES, 2011).

Outro aspecto importante é a convulsão, isto é, descargas elétricas cerebrais que se propagam por todas as regiões do cérebro - desencadeadas por uma ativação anormal e desordenada dos neurônios do sistema nervoso central - e que se manifestam por alterações comportamentais, movimentos desordenados ou mesmo olhar fixo, sem interação com o ambiente (SANTORO, 2011).

Não se pode esquecer a hemorragia, definida como a ruptura ou laceração de um vaso sanguíneo com o extravasamento de seu conteúdo. As hemorragias podem ser externas, quando ocorre o extravasamento do sangue para fora do corpo e internas, quando não há sangramento aparente no exterior, provocando alterações fisiológicas. Normalmente é diagnosticada após episódios de diarreias e vômitos com sangue (QUILICl; TIMERMAN, 2011; SANTORO, 2011; MORAES, 2011).

Há, também, as queimaduras que são lesões teciduais provocadas pela transferência de energia de uma fonte de calor para o corpo e podem ser 
ocasionadas por corrente elétrica, agentes térmicos (irradiação solar, líquidos superaquecidos, vapor, fogo, gelo), produtos químicos (solventes, soda cáustica, alvejantes) e agentes radioativos. As queimaduras representam a quarta causa de óbito no mundo, principalmente em pacientes jovens, de um a quarenta anos, e deixam, muitas vezes, marcas irreversíveis (QUILICl; TIMERMAN, 2011). As queimaduras são classificadas, conforme a profundidade e a extensão da lesão causada à pele, em de 1., 2. e 3. graus (QUILICl; TIMERMAN, 2011).

Há, além disso, os acidentes com animais peçonhentos que são os que produzem substâncias tóxicas e têm aparelhos adequados para inoculação dessas substâncias, ou seja, dentes ocos ou ferrões por onde passam ativamente os venenos. Em resumo: peçonhentos são animais que injetam veneno com facilidade e forma ativa (CIT, 2012).

\subsection{Legislação}

A legislação que dispõe sobre o atendimento de primeiros socorros em eventos na cidade de Florianópolis é a Lei n. ${ }^{0} 5.548 / 99$ em vigor desde 15 de outubro de 1999. Em suma, nessa lei, afirma-se a obrigatoriedade da "instalação de um ambulatório médico móvel em shows e competições esportivas ou outros eventos públicos, cuja presença de público ultrapasse cinco mil pessoas, tanto ao ar livre como em ambientes fechados". São da responsabilidade dos "promotores dos eventos" a contratação e as despesas decorrentes dos serviços prestados, assim como os equipamentos necessários para o funcionamento desse serviço e a instalação obrigatória de uma linha telefônica (convencional ou celular) no ambulatório médico móvel. Para a efetivação dessa lei, é necessário que seja reservado, no local do evento, um espaço de fácil acesso, para que seja montado o ambulatório, capaz de atender prontamente as pessoas que necessitarem de assistência médica de urgência. 
Nos eventos em que a presença do público "não ultrapasse cinco mil pessoas, deverá, obrigatoriamente, ter à disposição do público uma ambulância equipada para o pronto atendimento dos presentes". Esse ambulatório médico móvel deverá ser equipado de acordo com as exigências da Secretaria de Saúde e Desenvolvimento Social do Município.

Conforme o estatuto do torcedor, Lei n.o 10.671, de 15 de maio de 2003, em quaisquer competições esportivas, é dever da entidade responsável pela organização da competição "disponibilizar um médico e dois enfermeirospadrão para cada dez mil torcedores presentes à partida; disponibilizar uma ambulância para cada dez mil torcedores presentes à partida; e comunicar previamente à autoridade de saúde a realização do evento".

\section{Metodologia}

Os procedimentos metodológicos elencados no desenvolvimento deste estudo basearam-se em dois momentos distintos e igualmente importantes para cumprirem-se os objetivos aqui propostos.

Na primeira etapa, realizaram-se pesquisas bibliográficas e documentais. Para atingir os demais objetivos e com a finalidade de verificar os conhecimentos dos organizadores de eventos em primeiros socorros, fez-se pesquisa de caráter quantitativo, por meio do método survey, com perguntas abertas e fechadas, aos organizadores de eventos, atuantes na grande Florianópolis. A aplicação do questionário ocorreu da segunda quinzena de abril de 2013 até a primeira quinzena de maio do mesmo ano, com uma amostra não probabilística por conveniência, totalizando 29 participantes.

A seleção dos profissionais para participar da pesquisa ocorreu de forma aleatória, e o critério era que os sujeitos atuassem no setor de eventos, autônomos ou pertencentes a empresas do setor, atuantes na organização ou operacionalização de eventos de pequeno, médio ou grande portes. O convite 
para participar da pesquisa foi realizado via e-mail, a fim de comunicar a todos os organizadores de eventos de forma igual e no mesmo período. Na pesquisa, enviou-se o link do questionário para todos os organizadores de eventos cadastrados na ABEOC-SC - Associação Brasileira de Empresas de Eventos na grande Florianópolis -, porém, de acordo com o preenchimento por livre manifestação e consentimento, não se atingiu grande parcela da população pesquisada.

A princípio, apresentou-se o tema da pesquisa com os objetivos (gerais e específicos) e, em seguida, os organizadores de eventos foram convidados a participar, respeitando-se a Resolução n. ${ }^{\circ}$ 196/96, que confere as normas de ética para a realização de pesquisa que envolve seres humanos. Assim, contavase com o termo de consentimento livre e esclarecido, que os organizadores assinaram e enviaram por meio eletrônico, garantindo-lhes o anonimato. 0 questionário também deveria ser respondido de forma anônima, em formulário eletrônico específico, evitando-se, pois, constrangimentos. Após a coleta de dados, houve análise e descrição em forma de redação científica.

\section{Relato dos Dados da Pesquisa}

No estudo em tela, procurou-se verificar as atitudes dos organizadores de eventos, ante as situações de urgência e emergência que ocorrem durante os eventos e por meio da análise da pesquisa. Assim, apresentam-se, no quadro abaixo, os resultados obtidos por meio do método de coleta de material empírico utilizado neste estudo. 
Quadro 1. Resultado do questionário de pesquisa

\begin{tabular}{|c|c|c|}
\hline \multirow{3}{*}{ 1) Tempo de experiência na área de eventos } & Até um ano & $31 \%$ \\
\hline & De um a oito anos & $41 \%$ \\
\hline & Mais de oito anos & $28 \%$ \\
\hline \multirow{2}{*}{$\begin{array}{l}\text { 2) Indicação de telefones do Corpo de Bombeiros e do } \\
\text { SAMU }\end{array}$} & Resposta correta & $56 \%$ \\
\hline & Resposta incorreta & $44 \%$ \\
\hline \multirow{3}{*}{ 3) Indicação sobre quais são os sinais vitais } & Resposta correta & $20 \%$ \\
\hline & $\begin{array}{l}\text { Resposta parcialmente } \\
\text { correta (incompleta) }\end{array}$ & $52 \%$ \\
\hline & Resposta incorreta & $28 \%$ \\
\hline \multirow{2}{*}{ 4) Ação correta em relação a queimaduras } & Resposta correta & $12 \%$ \\
\hline & Resposta incorreta & $88 \%$ \\
\hline \multirow{3}{*}{$\begin{array}{l}\text { 5) Procedimentos adequados em relação a fraturas, } \\
\text { luxações e entorses }\end{array}$} & Resposta correta & $16 \%$ \\
\hline & $\begin{array}{l}\text { Resposta parcialmente } \\
\text { correta (incompleta) }\end{array}$ & $68 \%$ \\
\hline & Resposta incorreta & $16 \%$ \\
\hline \multirow{2}{*}{$\begin{array}{l}\text { 6) Procedimento adequado em caso de ferimentos que } \\
\text { apresentam sangramentos }\end{array}$} & Resposta correta & $81 \%$ \\
\hline & Resposta incorreta & $19 \%$ \\
\hline \multirow{3}{*}{ 7) Procedimento adequado em caso de engasgo } & Resposta correta & $68 \%$ \\
\hline & $\begin{array}{l}\text { Resposta parcialmente } \\
\text { correta (incompleta) }\end{array}$ & $20 \%$ \\
\hline & Resposta incorreta & $12 \%$ \\
\hline \multirow{2}{*}{ 8) Procedimento adequado em relação à convulsão } & Resposta correta & $69 \%$ \\
\hline & Resposta incorreta & $31 \%$ \\
\hline \multirow{2}{*}{$\begin{array}{l}\text { 9) Conhecimento sobre legislação referente ao } \\
\text { atendimento de urgência e emergência em eventos }\end{array}$} & $\begin{array}{l}\text { Conhece alguma lei sobre o } \\
\text { tema abordado }\end{array}$ & $17 \%$ \\
\hline & Não conhece & $83 \%$ \\
\hline
\end{tabular}


Verificou-se que a maioria dos organizadores de eventos participantes deste estudo demonstra um conhecimento prévio em primeiros socorros, porém, ao observar-se o Quadro 1, constata-se a insuficiência para a realização de alguns procedimentos, o que comprova que os sujeitos da pesquisa apresentam uma deficiência em relação ao atendimento como um todo, tornando o procedimento incompleto, o que favoreceria complicações às intercorrências de saúde apresentadas. Considera-se essa constatação relevante, uma vez que tal atitude pode contribuir negativamente para o socorro de uma vítima.

O fato supracitado pode ter como uma das justificativas a ausência de treinamento em primeiros socorros nas grades curriculares dos cursos em que se formam organizadores de eventos. Também foi possível verificar que $69 \%$ dos respondentes têm experiência na organização e operacionalização de eventos, porém esse fato não significa que ele sabe como agir em situações de urgência e emergência.

Quando questionados sobre o conhecimento da legislação que obriga ao atendimento de urgência e emergência em eventos, $83 \%$ dos profissionais pesquisados desconheciam essa legislação, ficando evidente o descumprimento das normas. Além disso, evidencia-se a necessidade de uma legislação mais descritiva sobre a obrigatoriedade de ambulância e equipe de socorro em eventos, definindo-se melhor a tipologia e o porte de eventos em que serão necessários tais profissionais, assim como a quantidade de socorristas em eventos.

\section{Considerações Finais}

O conhecimento em primeiros socorros pode ser a diferença entra a vida e a morte de uma pessoa. Em eventos, há inúmeros riscos aos quais todos os 
envolvidos estão expostos. Neste estudo, buscou-se desvendar a capacidade de atuação do organizador de evento em uma situação de socorro urgente, o que, além de dar conforto à vítima, pode fazer a diferença no estado clínico, como reabilitação precoce, tempo reduzido de internação hospitalar e redução e/ou inexistência de sequelas.

Todos os cidadãos devem ter conhecimentos em procedimentos de primeiros socorros, assim como a mudança comportamental em relação à segurança. Conforme Trindade (2010), "saber o que fazer e o que não fazer ante um acidente ou um mal súbito é, em primeiro lugar, uma questão de cidadania, de solidariedade e de amor ao próximo".

Ao concluir este estudo, verificou-se que a maioria dos organizadores de eventos tem um conhecimento em primeiros socorros, entretanto insuficiente para a realização de atendimentos em situações de urgência e emergência. Notou-se, ainda, a importância de um programa de treinamento em primeiros socorros para os organizadores de eventos, assim como a criação de material de consulta sobre o tema. Tais práticas visam a não só desenvolver ações de prevenção a agravos à saúde, como também à promoção da saúde, minimizando, assim, os danos advindos da incorreta manipulação da vítima e da falta de socorro imediato. Esses fatos elencados podem contribuir para o agravamento do estado da vítima, e, mais que isso, resultar em maior tempo de permanência hospitalar em razão de complicações.

Assim, há necessidade de ações preventivas em relação ao planejamento e ao mapeamento de riscos em eventos, no sentido de aumentar a segurança de todos os envolvidos e diminuir os riscos que levam a situações de urgências e emergências. 


\section{Referências}

ANDRADE, R. B. Manual de eventos. 3. ed. Caxias do Sul: EDUCS, 2007.

BRASIL. Decreto-Lei n. ${ }^{\circ}$ 2.848, de 7 de dezembro de 1940. Código penal. Disponível em: < http://www.planalto.gov.br/ccivil_03/decreto-lei/del2848.htm>. Acesso em: 13 jun. 2011.

Lei.$^{\circ}$ 10.671, de 15 de maio de 2003. Dispõe sobre o Estatuto de Defesa do Torcedor e dá outras providências. Disponível em: <http://www.planalto.gov.br/ccivil_03/leis/2003//10.671.htm>. Acesso em: 9 ago. 2012.

Lei n.o 11.771, de 17 de setembro de 2008. Dispõe sobre a Política Nacional de Turismo e dá outras providências. Disponível em: <http://www.planalto.gov.br/ccivil_03/_ato2007-2010/2008/lei//11771.htm>. Acesso em: 6 fev. 2014

BRITTO, J.; FONTES, N. Estratégias para eventos: uma ótica do marketing e do turismo. São Paulo, SP: Aleph, 2002.

CFM - CONSELHO FEDERAL DE MEDICINA. Resolução CFM no 1.451/95. Disponível em: <http://www.portalmedico.org.br/resolucoes/cfm/1995/1451_1995.htm>. Acesso em: 7 ago. 2012.

CIT - CENTRO DE INFORMAÇÃO TOXICOLÓGICA. Animais peçonhentos. Disponível em: <http://www.cit.rs.gov.br/index.php?option=com_content\&view=category\&layout=blog\&i $\mathrm{d}=4 \&$ Itemid=56>. Acesso em: 20 ago. 2012.

DONADEL, W. B. Projeto bombeiro na escola: ensinando primeiros socorros nas aulas de educação física - $\quad$ Florianópolis, 2011. Disponível em: <http://biblioteca.cbm.sc.gov.br/biblioteca/index.php/component/docman/search_result> . Acesso em: 22 ago. 2012.

FLORIANÓPOLIS. Lei n.o 5.548 de 15 de outubro de 1999. Obrigatoriedade de funcionamento de ambulatório médico móvel e dá outras providências. Disponível em: <http://www.jusbrasil.com.br/legislacao/995251/lei-5548-99-florianopolis>. Acesso em: 12 ago. 2012.

HORTA, W. A. Processo de enfermagem. Ribeirão Preto: Pedagógica, 1979.

JORNAL NACIONAL. Noivo morre após cair sobre taça de vidro durante casamento no RJ. Rio de Janeiro, Rede Globo, edição de 20 nov. 2012. Disponível em: <http://g1.globo.com/jornalnacional/noticia/2012/11/noivo-morre-apos-cair-sobre-taca-de-vidro-durante-casamentono-rj.html>. Acesso em: 7 mar. 2013.

MATIAS, M. Organização de eventos: procedimentos e técnicas. Barueri: Manole, 2004.

MEIRELLES, G. F. Tudo sobre eventos. São Paulo: STS, 1999.

MORAES, M. V. G. Atendimento pré-hospitalar: treinamento da brigada de emergência do suporte básico ao avançado. São Paulo: látria, 2010. 
MOREIRA, F. C. Palco cai e fere 11 em baile de formatura no Espéria. Diário de São Paulo, 5 mar. 2007. Disponível em: http://extra.globo.com/noticias/brasil/palco-cai-fere-11-em-baile-deformatura-no-esperia-739902.html\#ixzz2TrSkZ1vx. Acesso em: 3 dez. 2012.

QUILICI, A. P.; TIMERMAN, S. Suporte básico de vida: primeiro atendimento na emergência para profissionais de saúde. Barueri, São Paulo: Manole, 2011

ROSSA, J. C.; FERREIRA, G. M. L. Nível de conhecimento de primeiros socorros de todos os professores e funcionários administrativos de uma escola municipal de Medianeira - PR. Disponível em: <http://www.faesi.com.br/index.php?option=com_content\&view=article\&id=239:nivel-deconhecimento-de-primeiros-socorros-de-todos-os-professores-e-funcionariosadministrativos-d\&catid=75:portal-do-saber\&Itemid=222>. Acesso em: 27 ago. 2012. 


\section{Bruna Dorabiallo de Oliveira}

Professora efetiva do Instituto Federal de Educação Ciência e Tecnologia de Santa Catarina IFSC

Mestranda do programa de Pós-Graduação em Turismo da Universidade Federal do Paraná UFPR

Especialista em Marketing Empresarial pela Universidade Federal do Paraná - UFPR - (2010) Graduada em Tecnologia em Comunicação Institucional pela Universidade Tecnológica Federal do Paraná - UTFPR - (2009), e em Turismo pela Pontifícia Universidade Católica do Paraná PUC/PR - (2009) com extensão em docência do ensino superior bruna.dorabiallo@ifsc.edu.br Rua Quatorze de Julho, 150 - Estreito, Florianópolis - SC, 88075-010

\section{Luciane Patrícia Oliari}

Professora efetiva do Instituto Federal de Educação Ciência e Tecnologia de Santa Catarina IFSC

Mestranda no Programa de Pós- Graduação em Enfermagem da Universidade Federal de Santa Catarina

Especialista em Enfermagem do Trabalho pelo Instituto Brasileiro de Pós-Graduação e Extensão - IBPEX - (2010) e em Educação Profissional Integrada à Educação Básica na Modalidade Jovens e Adultos pelo Instituto Federal de Educação Ciência e Tecnologia (2011)

Graduada em Enfermagem pelo Instituto Superior e Centro Educacional Luterano Bom Jesus IELUSC - (2008)

lucianep@ifsc.edu.br

Rua Quatorze de Julho, 150 - Estreito, Florianópolis - SC, 88075-010 